\title{
Peran Dukungan Sosial dalam Lingkungan Kerja terhadap Burnout Pada Prajurit TNI
}

\author{
Danik Dwi Suprapti ${ }^{1}$ \\ Fakultas Psikologi, Universitas Muhammadiyah Malang \\ email1'danikdwi01@gmail.com
}

\begin{abstract}
Heavy workloads and uncertain working hours on TNI soldiers can trigger burnout. With the existence of burnout, social support from people around is expected to be able to contribute to preventing or reducing the level of burnout on TNI soldiers. The purpose of this study is to find out a contribution from social support in the work environment to burnout in the army. Respondents in the study were 202 people aged 21-30 years with a work period of more than one year. The data collection technique used in this study was purposive sampling. In this study, social support that acts as a variable (X) was measured by instruments from Adrian in 2014 which obtained a reliability value of 0.925 . Whereas, to measure burnout which acts as a variable $(Y)$ the MBI (Maslach Burnout Scale) instrument was used which was tested by Andarini in 2018 with a reliability value of 0.902 . In this study, the data obtained were analyzed using simple linear regression with the results that showed that there was a negative effect of social support on burnout on Army soldiers $(B=-0.482)$. It can be explained that the higher the social support received, the burnout experienced will be low. Conversely, if the social support received is low, the level of burnout experienced will be even higher. Based on research results, social support has a contribution of $24 \%$ to burnout.
\end{abstract}

KEYWORDS Social support, Burnout, TNI AD

CITATION Suprapti, D.D. (2020). Peran dukungan sosial dalam lingkungan kerja terhadap burnout pada prajurit TNI. Cognicia, 8, (2). 252-

Burnout merupakan suatu keadaan dimana seseorang merasakan kelelahan emosional, mental dan fisik yang berlebihan dalam suatu pekerjaan (Jeung, Kim \& Chang, 2018). Burnout merupakan suatu kondisi yang disebabkan oleh tuntutan pekerjaan yang berkepanjangan, sehingga hal tersebut mempengaruhi kesejahteraan dari pekerja, berkurangnya kinerja, meningkatnya absensi serta keingininan untuk meninggalkan pekerjaan tersebut (Szczgiel \& Mikolajczak, 2018). Istilah burnout pertama kali dideskripsikan oleh Herbert Freudenberger yang berprofesi sebagai seorang psikolog klinis di New York. Menurut Freudenberger (dalam Jeung, Kim \& Chang, 2018) burnout merupakan suatu kondisi yang terjadi pada individu yang bekerja terlalu banyak, bekerja dengan waktu yang terlalu lama dan bagi mereka yang terlalu intens dengan pekerjaan yang dilakukannya.

Burnout akan muncul dalam bentuk sikap yang negatif seperti penurunan kinerja, produktifitas kerja (Jeung, Kim \& Chang, 2018), menimbulkan stress kerja (Lee, Wu \& Du, 2019), keinginan yang tinggi untuk meninggalkan pekerjaan (Gharakhani, 2019) hal tersebut didapat dari kontak dengan lingkungan kerja yang lama dan tekanan dari suatu pekerjaan, dan menurunkan komitmen berorganisasi karena kurangnya penghargaan yang 
diterima tidak sesuai dengan pekerjaan yang telah dilakukan (Tawale, Budi \& Nurcholis, 2011) Pada penelitian Coplan, McCall, Smith \& Essary (2018) dijelaskan bahwa sebanyak $55,6 \%$ pekerja menyatakan bahwa mereka menghabiskan waktunya di tempat kerja.

Burnout dapat terjadi pada siapa saja, dari bidang pekerjaan pelayanan sosial seperti perawat, guru dan anggota keamanan karena tingkat kelelahan yang mereka alami lebih tinggi (Andriani dan Helmayunita, 2019). Penelitian terdahulu menjelaskan bahwa burnout dipengaruhi oleh kecerdasan emosional (Szczgiel dan Mikolajczak, 2018). Hal ini dibuktikan dari penelitian yang dilakukan oleh Imaniar \& Sularso (2016) bahwa kecerdasan emosional memiliki pengaruh yang signifikan terhadap burnout. Semakin tinggi tingkat kecerdasan emosional pada individu maka semakin rendah tingkat burnout pada individu. Burnout dapat dipengaruhi oleh beberapa hal seperti pengalaman kerja yang minim (Eliyana, 2016), pemberian reward (Swasti, Ekowati \& Rahmawati, 2017), workfamily conflict, kualitas pemimpin dalam suatu pekerjaan, dan konflik dengan rekan kerja (Handoko \&Yuniawan, 2017).

Pada penelitian Pradana, Kristanto \& Hidayat (2017) dinyatakan bahwa burnout dapat dipengaruhi oleh lingkungan kerja. Dengan adanya lingkungan kerja yang baik maka potensi untuk mengalami burnout akan semakin rendah. Burnout dapat terjadi karena kurangnya motivasi, lingkungan kerja yang kurang mendukung, hubungan dengan rekan kerja yang kurang harmonis, pekerjaan yang monoton dan pekerjaan yang mendesak dimana pekerja dituntut untuk harus segera menyelesaikan pekerjaan yang diberikan oleh atasan (Hartanti, 2018). Menurut penelitian Adnyaswari \& Adnyani (2017), burnout dipengaruhi oleh social support. Berdasarkan penelitian tersebut dijelaskan bahwa semakin tinggi social support maka kinerja individu semakin baik. Beberapa pekerja mengalami burnout dikarenakan memiliki masalah krusial seperti jam kerja yang lebih panjang, beban kerja yang berat dan melebihi batas wajar, tekanan kerja, gaji yang tidak sesuai dan perlakuan yang tidak adil (Adnyaswari \& Adnyani, 2017). Tetapi tingkat burnout dapat berkurang dengan adanya dukungan sosial. Pada penelitian Andriani (2019) yang dilakukan kepada guru, didapatkan bahwa dukungan sosial yang tinggi akan mengurangi tingkat burnout.

Dukungan sosial akan memberikan rasa nyaman serta aman ketika seseorang mengalami peristiwa yang berat (Santoso \& Setiawan, 2018). Dukungan sosial dapat mengurangi tingkat stress pada karyawan (Iswanto \& Agustina, 2016). Dukungan sosial adalah suatu perasaan didukung oleh rekan kerja dalam organisasi tempat mereka bekerja (Tufail, 2016). Menurut Gotlieb (Dhamayantie, 2018) dukungan sosial merupakan suatu informasi verbal atau non verbal yang diberikan oleh orang lain. Menurut Smet, dukungan sosial yaitu suatu pertolongan serta bantuan yang diterima oleh individu yang didapat dari interaksinya dengan lingkungan (Putra dan Susilawati, 2018). Pemberian dukungan sosial kepada individu dapat memberikan dampak positif seperti mampu mencegah adanya beban kerja yang berat, kelelahan kerja, work-family conflict (Pluut, Curşeu, \& Liu, 2018), mampu mengurangi stress (Putra \& Susilawati, 2018), dapat meningkatkan kualitas organisasi melalui hubungan interpersonal antar karyawannya (Tufail, 2016), mengurangi tingkat kelelahan emosional dan dapat meningkatkan prestasi pribadi (Woodhead, 2016).

Dukungan sosial dalam lingkungan kerja dapat diberikan oleh rekan kerja serta atasan. Dengan adanya dukungan sosial, beban maupun permasalahan yang sedang dihadapi individu dapat berkurang (Wulandari, 2018), mampu meningkatkan semangat dan motivasi kerja bagi karyawan (Yulia, 2017), serta dapat menurunkan burnout yang 
dialami oleh kayawan Andriani (2019). Dengan adanya dukungan sosial individu akan merasakan kenyamanan, diperdulikan, serta merasa bahwa ia diterima oleh lingkungannya (Santoso \& Setiawan, 2018). Berdasarkan penjelasan sebelumnya, penelitian ini menggunakan dukungan sosial sebagai variabel $\mathrm{X}$ dikarenakan terdapat penelitian dari Nie, dkk (2015) yang menyatakan bahwa dukungan sosial tidak berkaitan dengan terjadinya burnout. Sedangkan, Romadhoni, Asmony \& Suryatni (2015) menyatakan bahwa dukungan sosial memiliki kontribusi terhadap burnout. Dengan adanya hal tersebut, dilakukan penelitian kembali mengenai peran dari dukungan sosial terhadap burnout untuk mengetahui apakah terdapat kontribusi dari dukungan sosial terhadap burnout.

Penelitian ini dilakukan kembali kepada populasi yang berbeda, yaitu kepada prajurit TNI AD dikarenakan adanya potensi untuk mengalami burnout yang tinggi. Dengan adanya beban kerja yang berat, bekerja dengan waktu yang lama dan tidak tentu, serta bekerja terlalu intens dapat memicu timbulnya burnout. Berdasarkan wawancara singkat yang telah dilakukan kepada salah satu anggota prajurit TNI AD, didapatkan informasi bahwa mereka memiliki tugas pokok seperti menjaga kedaulatan negara, mempertahankan keutuhan wilayah, dan tugas berat lainnya seperti ketika ditugaskan untuk menjaga wilayah perbatasan dimana daerah tersebut rawan untuk mengalami konflik. Selain itu, salah satu anggota TNI AD tersebut juga menyatakan jika mereka memiliki jam kerja yang panjang serta harus siap siaga ketika dibutuhkan kapanpun, sehingga mereka seringkali mengalami kelelahan yang berlebih. Untuk mengatasi hal tersebut, dukungan sosial dari orang-orang sekitarnya sangat dibutuhkan. Penelitian ini menggunakan dukungan sosial sebagai variabel $X$ dikarenakan pada penelitian-penelitian sebelumnya burnout lebih sering dikaitkan dengan variabel lain seperti work-family conflict (Rubab, 2018). Selain itu, pada penelitian-penelitian sebelumnya burnout seringkali dilakukan kepada para pekerja medis. Maka, tujuan dari penelitian ini adalah untuk mengetahui kontribusi dari dukungan sosial terhadap burnout pada prajurit TNI AD.

\section{METODE PENELITIAN}

Pada penelitian ini digunakan pendekatan kuantitatif non eksperimen dimana penelitian yang dilakukan yaitu dengan menyebarkan skala kepada responden. Data yang didapat pada penelitian ini diubah menjadi angka-angka dan diolah dengan menggunakan teknik statistik. Subjek dalam penelitian ini adalah prajurit TNI AD yang berjumlah 202 orang dengan kriteria telah menikah maupun belum menikah, berusia 20-30 tahun dan pengalaman kerja minimal satu tahun. Alasan digunakannya sampel adalah karena karakteristik pekerjaan dari prajurit TNI memiliki beban kerja yang berat serta jam kerja yang tidak tentu sehingga ber potensi untuk mengalami burnout. Teknik pengambilan sampling pada penelitian ini yaitu purposive sampling. Teknik pengambilan ini digunakan dengan cara menetapkan ciri khusus yang sesuai dengan tujuan penelitian yang diharapkan agar terjawabnya suatu permasalahan penelitian.

Pada penelitian ini terdapat dua variabel, yaitu dukungan sosial $(\mathrm{X})$ dan burnout $(\mathrm{Y})$. Dukungan sosial adalah suatu perhatian atau kepedulian yang diberikan oleh orang lain seperti rekan kerja dan atasan. Perhatian serta kepedulian yang dimaksudkan yaitu seperti adanya penghargaan dan pertolongan. Dengan adanya dukungan sosial, prajurit TNI akan merasa bahwa orang-orang disekitarnya menyayanginya, menghargainya, serta mengakui keberadaannya. Dukungan sosial memiliki lima aspek di dalamnya, yaitu dukungan 
emosional, dukungan instrumental, dukungan informasi, penghargaan, dan dukungan kelompok sosial.

Variabel X pada penelitian ini diukur dengan skala dukungan sosial dari Adrian (2014) yang diadaptasi dari aspek-aspek pada teori Sarafino dengan jumlah 33 item pernyataan. Namun, skala tersebut diuji coba kembali kepada para anggota Polisi Sabhara di Polres Malang oleh Hayati (2017) dan didapatkan 28 item pernyataan yang valid. Salah satu contoh item dari dukungan sosial yaitu "rekan kerja memberikan dorongan agar saya tetap semangat bekerja". Seseorang dapat dikatakan mendapat dukungan sosial yang tinggi apabila berada di rentang skor $\geq 93$ dan akan dikatakan mendapat dukungan sosial yang rendah apabila skor yang didapat sebanyak 45 .

Alat ukur dalam penelitian ini menggunakan skala likert yang disusun dengan sistem favorable dan unfavorable. Untuk variabel dukungan sosial, setiap pernyataan yang diberikan terdapat empat pilihan jawaban yaitu Sangat Setuju (SS), Setuju (S), Tidak Setuju (TS), dan Sangat Tidak Setuju (STS). Pada item pernyataan favorable, jawaban Sangat Setuju (SS) akan mendapatkan nilai 4, Setuju (S) dengan nilai 3, pilihan jawaban Tidak Setuju (TS) mendapat nilai 2 dan pilihan jawaban Sangat Tidak Setuju (STS) akan mendapatkan nilai 1. Sementara itu, untuk pernyataan unfavorable pilihan jawaban Sangat Setuju (SS) memiliki nilai 1, Setuju (S) mendapatkan nilai 2, pilihan jawaban Tidak Setuju (TS) mendapatkan nilai 3, dan untuk pilihan jawaban Sangat Tidak Setuju (STS) akan mendapatkan nilai 4.

Selanjutnya, pada variabel Y yaitu burnout adalah suatu kondisi dimana individu merasakan kelelahan yang berlebih, baik kelelahan secara emosional, mental, maupun fisik. Kelelahan secara emosional yang dimaksudkan yaitu seperti adanya perasaan bosan atas pekerjaannya, mudah tersinggung dengan ucapan atau perilaku dari orang-orang disekitarnya serta mudah putus asa. Sedangkan, kelelahan secara mental bagi orang yang mengalami burnout yaitu adanya sikap yang negatif terhadap orang lain, acuh tak acuh terhadap lingkungan sekitar, dan seringkali menganggap bahwa dirinya tidak berharga. Selanjutnya, untuk kelelahan secara fisik yang dimaksudkan dalam hal ini akan mengarah kepada hal-hal yang dapat dilihat secara langsung seperti mengalami sakit kepala, sakit punggung, mengalami masalah dengan pola tidur dan rasa letih yang berlebihan. Prajurit yang mengalami burnout dapat disebabkan oleh beberapa hal seperti jam kerja yang terlalu panjang, beban pekerjaan yang berat, hubungan antar rekan kerja yang kurang harmonis, pekerjaan yang monoton hingga gaji yang tidak sesuai dengan pekerjaan yang telah dilakukan. Individu yang mengalami burnout seringkali merasakan perasaaan bersalah, tidak mampu, tidak kompeten dan merasa sulit untuk merasakan keadaan yang mereka alami, baik di tempat kerja maupun di rumah. Burnout memiliki tiga faktor yang dijelaskan di dalamnya yaitu emotional exhaustion, depersonalization, dan reduced personal accomplishment.

Instrument variabel Y pada penelitian ini diadaptasi dari Maslach Burnout Inventory (MBI) yang dikembangkan oleh Maslach dan Jackson (1981) yang berjumlah 21 item pernyataan (dalam Andarini, 2018). Salah satu contoh pada variabel ini yaitu "saya tidak mampu menciptakan suasana yang santai dengan rekan kerja”. Dalam variabel ini, seseorang dikatakan mengalami burnout yang rendah apabila skor nilai mean berada diantara 1-1,75. Namun, apabila nilai mean seseorang pada variabel ini berada direntang angka 1,76-2,50 maka individu tersebut dikatakan harus segera mendapatkan penanganan untuk mengurangi tingkat burnout yang dialaminya. Sedangkan, individu yang dikatakan mengalami urgent dalam burnout yaitu apabila memiliki nilai mean antara 2,51 hingga > 3,25.

Alat ukur yang digunakan pada penelitian ini yaitu skala likert dimana pada 
pernyataan favorable terdapat pilihan jawaban Selalu (SL) yang memiliki skor 4, Sering (SR) dengan skor 3, Jarang (JR) dengan skor 2, dan Tidak Pernah (TP) dengan skor 1. Lalu untuk pernyataan unfavorable pada variabel burnout, pilihan jawaban Selalu (SL) akan mendapatkan skor 1, Sering (SR) dengan skor 2, Jarang (JR) dengan skor 3, dan Tidak Pernah (TP) dengan skor 4.

Penelitian dilakukan melalui tiga tahap, tahap pertama yaitu dimulainya persiapan. Pada tahap ini, peneliti melakukan pendalaman materi melalui kajian teoritik. Dalam hal ini, peneliti menggunakan alat ukur yang didapat dari penelitian sebelumnya dimana pada skala tersebut didasarkan pada aspek-aspek dari variabel X dan Y. Pada tahap kedua, peneliti menyebarkan skala pada tanggal 16 Desember 2019 sampai 31 Desember 2019 kepada para prajurit TNI AD yang telah memenuhi kriteria pada penelitian ini. Pada tahap terakhir, peneliti menganalisa hasil yang didapatkan dari penyebaran skala kepada 230 responden. Data yang diperoleh diinput dan diolah dengan menggunakan Statistical Package For Social Science (SPSS) 21, yaitu dengan menggunakan analisis uji regresi.

\section{HASIL PENELITIAN}

Pada penelitian ini, subjek yang berpartisipasi yaitu 202 prajurit TNI AD yang telah bekerja lebih dari satu tahun dan berusia antara 20-28 tahun. Alasan digunakannya prajurit TNI AD sebagai sampel dalam penelitian ini dikarenakan mereka memiliki beban kerja yang berat serta jam kerja yang panjang. Total subjek dalam penelitian ini sebanyak 235 orang, namun data yang diolah berjumlah 202 dikarenakan 33 subjek lainnya tidak memenuhi kriteria yang telah ditentukan sebelumnya. Berikut ini adalah data demografis dari subjek yang berpartisipasi dalam penelitian yang telah dilakukan.

\section{Tabel 1. Responden Penelitian}

\begin{tabular}{lcc}
\hline \multicolumn{1}{c}{ Kategori } & Subjek & Persentase \\
\hline Usia & & \\
$20-24$ tahun & 115 & $57 \%$ \\
$25-28$ tahun & 87 & $43 \%$ \\
Status Pernikahan & & \\
Menikah & 1 & $0,5 \%$ \\
Belum Menikah & 201 & $99,5 \%$ \\
\hline
\end{tabular}

Berdasarkan tabel di atas, diketahui bahwa partisipan dalam penelitian ini yaitu 202 prajurit TNI. Jumlah responden terbanyak berada direntang usia 20-24 tahun sebanyak 115 responden dengan persentase sebesar $57 \%$. Sedangkan, untuk responden terendah berada di usia 25-28 tahun yang berjumlah 87 orang dengan persentase sebesar $43 \%$. Pada tabel di atas diketahui bahwa responden dengan status menikah berjumlah 1 orang dengan persentase 0,5\% dan 201 responden belum menikah dengan persentase 99,5\%.

Tabel 2. Data Deskriptif

\begin{tabular}{llll}
\hline Variabel & Mean & Std. & Deviation \\
\hline Dukungan Sosial & 89,53 & 5,425 & \\
Burnout & 1,94 & 0,029 & \\
\hline
\end{tabular}

Berdasarkan tabel di atas, variabel dukungan sosial memiliki variasi subjek sebesar 5,425 
dan nilai mean sebesar 89,53 dimana dengan skor tersebut dapat dikatakan bahwa subjek mendapat dukungan sosial yang sedang. Selanjutnya, pada variabel burnout variasi subjek yang didapat sebesar 0,029 dengan mean sebesar 1,94 dimana dengan skor tersebut individu berada ditingkat burnout sedang dan harus segera diatasi. Hal tersebut dikarenakan burnout akan meningkat seiring berjalannya waktu apabila tidak segera ditangani.

Tabel 3. Skor Dukungan Sosial

\begin{tabular}{llcc}
\hline Kategori & Skor & Subjek & Persentase \\
Rendah & $\leq 45$ & 0 & $0 \%$ \\
Sedang & $<93$ & 156 & $77 \%$ \\
Tinggi & $\geq 93$ & 46 & $23 \%$ \\
\hline Jumlah & & 202 orang & $100 \%$ \\
\hline
\end{tabular}

Berdasarkan tabel skor dukungan sosial di atas, ditunjukkan bahwa sebanyak 156 responden dengan persentase $77 \%$ mendapatkan dukungan sosial yang berada di tingkat sedang. Sedangkan, sebanyak 46 responden dengan persentase $23 \%$ mendapat dukungan sosial tinggi karena mendapatkan skor $\geq 93$.

Tabel 4. Persentase Burnout

\begin{tabular}{|c|c|c|}
\hline Kategori & Skor & Persentase \\
\hline Rendah & $1-1,75$ & $14 \%$ \\
\hline Sedang & $1,76-2,1$ & $81 \%$ \\
\hline Tinggi & $>2,5$ & $5 \%$ \\
\hline Jumlah & 202 orang & $100 \%$ \\
\hline
\end{tabular}

Berdasarkan tabel di atas, dapat dijelaskan bahwa 14\% prajurit mengalami burnout ditingkat rendah, $81 \%$ prajurit dengan burnout ditingkat sedang, dan $5 \%$ prajurit yang mengalami burnout dengan tingkat yang tinggi.

Tabel 5. Deskripsi Uji Regresi Dukungan Sosial terhadap Burnout

\begin{tabular}{llccc}
\hline $\begin{array}{l}\text { Koefisien } \\
\text { Korelasi }(\mathbf{r})\end{array}$ & $\begin{array}{l}\text { Koefisien } \\
\text { Determinasi }\left(\mathbf{R}^{2}\right)\end{array}$ & Sig & B & Kesimpulan \\
\hline 0,490 & 0,240 & 0,000 & $-0,482$ & Signifikan \\
\hline
\end{tabular}

Berdasarkan tabel di atas, didapatkan nilai signifikansinya yaitu 0,000 dimana nilai tersebut lebih kecil dari taraf signifikansi yang digunakan yaitu $0,05(\mathrm{P}<0,05=0,000<$ 0,05). Hasil penelitian tersebut menjelaskan bahwa terdapat pengaruh negatif $(B=-0,482)$ antara dukungan sosial terhadap burnout pada prajurit TNI AD. Koefisien determinasi $\left(\mathrm{R}^{2}\right)$ pada tabel di atas yaitu 0,240 dimana terdapat kontribusi dari variabel bebas terhadap variabel terikat sebesar $24 \%$, sedangkan sisanya $76 \%$ dipengaruhi oleh variabel lain diluar penelitian ini.

\section{DISKUSI}

Berdasarkan penelitian yang telah dilakukan kepada 202 prajurit TNI AD, jumlah partisipan yang paling banyak dalam penelitian ini berusia 25 tahun sebanyak 41 orang 
prajurit dengan persentase sebesar $20,3 \%$ dan responden terendah yaitu prajurit dengan usia 28 tahun yang berjumlah 6 orang dengan persentase sebesar 3\%. Sebagian besar responden dalam penelitian ini berstatus belum menikah yaitu sebanyak 202 orang prajurit dengan persentase sebesar 99,5\% dan responden yang berstatus menikah yaitu berjumlah 1 orang dengan persentase sebesar $0,5 \%$. Prajurit TNI AD yang berpartisipasi dalam penelitian ini mendapatkan dukungan sosial yang sedang dari orang-orang disekitarnya, hal ini dibuktikan dari hasil penelitian yang didapatkan bahwa skor mean dalam dukungan sosial yang diterima sebesar 89,53. Sementara itu, untuk burnout dalam penelitian ini didapatkan nilai mean sebesar 1,94 dimana dengan skor tersebut dapat dikatakan jika prajurit TNI AD mengalami burnout ditingkat sedang dengan persentase sebesar $81 \%$.

Pada penelitian ini, koefisien regresi yang didapat yaitu -0,482. Dengan hasil tersebut, dapat dikatakan bahwa terdapat pengaruh negatif dari dukungan sosial terhadap burnout pada prajurit TNI AD. Hal ini menunjukkan bahwa semakin tinggi dukungan sosial yang didapat oleh prajurit TNI AD maka tingkat burnout yang dialaminya akan semakin rendah. Sebaliknya, apabila dukungan sosial yang diterima prajurit rendah maka tingkat burnout yang dialami akan semakin tinggi. Hasil penelitian ini membuktikan bahwa hipotesa yang menyatakan bahwa adanya pengaruh negatif dari dukungan sosial terhadap burnout pada prajurit TNI AD dapat diterima.

Hasil penelitian ini sejalan dengan penjelasan yang dikemukakan oleh Adnyaswari \& Adnyani (2017) pada penelitiannya yang dilakukan kepada guru. Penelitian tersebut membuktikan bahwa adanya pengaruh dari dukungan sosial terhadap burnout. Dalam penelitiannya dijelaskan apabila dukungan sosial yang didapat oleh guru tinggi, maka semakin rendah tingkat burnout yang dialaminya. Sebaliknya, apabila dukungan sosial yang didapat rendah maka individu tersebut rentan untuk mengalami burnout. Pada dasarnya setiap orang yang bekerja berpotensi untuk mengalami burnout. Namun, berdasarkan hasil observasi peneliti kepada lingkungan yang menaungi prajurit TNI, terdapat potensi yang tinggi untuk mengalami burnout karena tuntutan pekerjaan yang berat serta lingkungan kerja yang menuntut mereka untuk siaga setiap waktu.

Menurut penelitian Fiorilli (2017) yang dilakukan kepada guru, kepuasan serta ketikdakpuasan dukungan sosial yang diterima individu diprediksi dapat menyebabkan burnout. Woodhead (2016) menyatakan bahwa dukungan sosial memiliki kontribusi yang besar terhadap burnout, dengan adanya dukungan sosial yang baik akan mengurangi tingkat kelelahan emosional dan dapat meningkatkan prestasi pribadi pada individu. Beberapa penelitian mengenai burnout seringkali dilakukan kepada guru karena rentan mengalami burnout, tetapi tidak menutup kemungkinan apabila burnout akan terjadi pada pekerja dibidang militer.

Menurut Sarafino (Yanti dan Hermaleni, 2019) dukungan sosial merupakan suatu kenyamanan, kepedulian serta bantuan yang diberikan oleh individu atau kelompok. Dengan adanya dukungan sosial seseorang akan merasakan kenyamanan ketika bekerja, sehingga segala bentuk stres yang ada dalam pekerjaan akan semakin minim (Iswanto dan Agustina, 2016). Individu dengan dukungan sosial yang tinggi memiliki tingkat stres yang rendah dan dapat mengatasi permasalahan dengan hal-hal yang positif (Taylor, 2015; Raisa, 2016). Dengan mendapat dukungan sosial yang tinggi dari orang-orang disekitar, para prajurit TNI AD akan merasa bahwa mereka dihargai, diperhatikan, dan disayangi sehingga kinerja serta semangat kerja mereka akan semakin tinggi pula. Apabila prajurit tidak 
mendapatkan dukungan sosial dari orang-orang disekitarnya, mereka akan merasa bahwa orang-orang disekitarnya kurang menyanyangi serta menghargai dirinya, sehingga persepsi tersebut dapat berdampak pada kinerja yang mereka lakukan. Pada penelitian ini ditunjukkan bahwa 23\% prajurit TNI AD yaitu sebanyak 46 orang mendapat dukungan sosial yang tinggi. Sedangkan, sisanya yaitu 77\% atau sebanyak 156 orang prajurit mendapat dukungan sosial yang berada dikategori sedang. Berdasarkan hasil tersebut dapat diketahui bahwa sebagian besar prajurit TNI AD tidak mendapat dukungan sosial yang tinggi dari orang-orang disekitarnya sehingga mereka rentan untuk mengalami burnout.

Dukungan sosial pada penelitian ini memiliki kontribusi sebesar $24 \%$ terhadap burnout. Berdasarkan hasil tersebut, dapat dinyatakan bahwa terdapat $76 \%$ faktor lain yang dapat menyebabkan burnout pada prajurit. Beberapa faktor lain yang dapat menyebabkan burnout di luar dari dukungan sosial yaitu seperti kecerdasan emosional pada individu tersebut (Szczgiel dan Mikolajczak, 2018). Selain itu, terdapat faktor lain yang dapat menyebabkan terjadinya burnout seperti stress kerja (Priyantika, 2018). Berdasarkan penelitian dari Priyantika (2018) yang dilakukan kepada karyawan, dinyatakan bahwa semakin tinggi tingkat stress kerja yang dimiliki karyawan maka semakin besar pula mereka mengalami burnout.

\section{SIMPULAN DAN IMPLIKASI}

Berdasarkan hasil penelitian ini, hipotesa dapat diterima dikarenakan adanya pengaruh negatif dari dukungan sosial tehadap burnout pada prajurit TNI. Apabila dukungan sosial yang diberikan kepada prajurit tinggi, maka burnout yang mereka alami akan semakin rendah. Namun, apabila dukungan sosial yang diberikan rendah maka burnout yang dialami oleh prajurit akan semakin tinggi. Implikasi dari penelitian ini yaitu bagi orang-orang terdekat seperti rekan kerja, atasan atau komandan memiliki kontribusi yang besar terhadap prajurit tersebut. Dengan adanya dukungan sosial dari orang-orang terdekat, prajurit akan merasa bahwa mereka dihargai, disayangi, dianggap keberadaannya serta diakui kemampuannya. Sehingga, potensi mereka untuk mengalami burnout akan rendah. Dukungan sosial yang dapat diberikan kepada mereka yaitu seperti diberikannya perhatian, saran, feedback, bantuan tenaga, serta reinforcement atau reward atas pekerjaan yang telah mereka lakukan. Hasil penelitian ini dapat digunakan oleh divisi atau satuan yang menangani prajurit TNI sebagai salah satu referensi untuk program penyuluhan atau psikoedukasi mengenai pentingnya peran dukungan sosial terhadap pekerjaan agar mereka tidak mengalami burnout atau mengurangi tingkat burnout yang sedang mereka alami. Bagi peneliti selanjutnya yang akan melakukan penelitian ini kembali, diharapkan untuk menggunakan variabel lain seperti work-family conflict, emotional intelligence, dan lain sebagainya agar terdapatnya variasi penelitian serta untuk lebih mengembangkan kemampuan yang telah dimiliki.

\section{REFERENSI}

Adrian, A. (2014). Hubungan Dukungan Sosial Dengan Burnout Pada Perawat Instalasi Gawat Darurat Di Rumah Sakit Banda Aceh. Program Sarjana Universitas Syiah Kuala, Banda Aceh.

Adnyaswari, N. A., \& Adnyani, A. G. A. D,. (2017). Pengaruh Dukungan Sosial dan Burnout Terhadap Kinerja Perawat Rawat Inap RSUP Sanglah. E-Jurnal Manajemen Unud. 
6(5):2747-2500.

Andarini, E. (2018). Analisis Faktor Penyebab Burnout Syndrome dan Job Satisfaction Perawat di Rumah Sakit Petrokimia Gresik. Tesis, Program Pascasarjana Universitas Airlangga, Surabaya.

Andriani, C., \& Helmayuni, N. (2019). Burn Out Pada Agen Asuransi Ditinjau Dari Dukungan Sosial Keluarga Pada Pt Asuransi Umum Bumiputera Muda 1967 Cabang Padang. UNES Journal of Social and Economics Research (UJSER). 4(1): 34-41.

Coplan, B., McCall, T. C., Smith, N., Gellert, V. L., \& Essary, A. C. (2018). Burnout, job satisfaction, and stress levels of PAs. Journal of the American Academy of PAs, 31(9), $42-46$.

Dhamayantie, E. (2018). Peranan Dukungan Sosial Pada Interaksi Positif PekerjaanKeluarga dan Kepuasan Hidup. EKUITAS (Jurnal Ekonomi dan Keuangan), 18(2), 181-200.

Eliyana. (2016). Faktor-Faktir yang Berhubungan Dengan Burnout Perawat Pelaksana di Ruang Rawat Inap RSJ Provinsi Kalimantan Barat Tahun 2015. Jurnal ARSI. 2(3): 172-182.

Gharakhani, D., \& Zaferanchi, A. (2019). The Effect of Job Burnout on Turnover Intention with Regard to the Mediating Role of Job Satisfaction. Journal Of Health, 10(1), 109117.

Handoko, P. A., \& Yuniawan, A. (2017). Pengaruh Kualitas Kepemimpinan, Konflik Pekerjaan Keluarga, Dan Dukungan Sosial Terhadap Presenteism Dengan Burnout Sebagai Variabel Interving (Studi Pada Dinas Kependudukan Dan Pencatatan Sipil Kota Semarang. Diponegoro Journal Of Management. 6(4): 1-13

Hartanti, I. D., Supriyanto, A \& Ulfatin, N. (2018). Manajemen Penanganan Burnout Dalam Meningkatkan Kinerja Tenaga Administrasi Sekolah. Jurnal Administrasi dan Manajemen Pendidikan. 1(3): 347-357.

Hayati, L. N. (2018). Hubungan Dukungan Sosial Dengan Stres Kerja Pada Anggota Polisi Fungsi Sabhara. Program Sarjana Universitas Muhammadiyah Malang, Malang.

Imaniar, R. R. L., \& Sularsom R. A. (2016). Pengaruh Burnout Terhadap Kecerdasan Emosional, Self-Efficacy, dan Kinerja Dokter Muda Di Rumah Sakit Dr. Soebandi. Jurnal Maksipreneur. 5(2): 46-56.

Iswanto, F., \& Agustina, I. (2016). Peran Dukungan Sosial di Tempat Kerja Terhadap Keterikatan Kerja Karyawan. Mediapsi. 2(2):38-45.

Jeung, D. Y., Kim. C \& Chang, S. J: Emotional Labor and Burnout: A Review of The Literature, 2018, 59(2): 187-193.

Lee, C. Y., Wu, J. H \& Du. J. K. (2019). Work Stress And Occupational Burnout Among Dental Staff In A Medical Center. Journal of Dental Sciences. 14:295-301.

Maslach, C., \& Jackson, S. E. (1981). The Measurement of Experienced Burnout. Measurement of Burnout. 2:99-113.

Nie, Z., Jin, Y., He, L., Chen, Y., Ren, X., Yu, J., \& Yao, Y. (2015). Correlation of Burnout With Socisl Support in Hospital Nurses. International Journal of Clinical and Experimental Medicine. 8(10): 19144-19149.

Pluut, H., Ilies, R., Curşeu, P. L., \& Liu, Y. (2018). Social support at work and at home: Dualbuffering effects in the work-family conflict process. Organizational Behavior and Human Decision Processes, 146, 1-13. 
Pradana, B. A., Kristanto, R. S \& Hidayat, D. S., (2017). Pengaruh Lingkungan Kerja Dan Beban Kerja Terhadap Burnout Pada Perawat RSUD Kardinah Kota Tegal. Jurnal Magisma. 5(2): 61-70.

Putra, P. S. P., \& Susilawati, Luh. K. P. (2018). Hubungan Antara Dukungan Sosial Dan Self Efficacy Dengan Tingkat Stres Pada Perawat Di Rumah Sakit Umum Pusat Sanglah. Jurnal Psikologi Udayana. 5(1):145-157.

Romadhoni, L. C., Asnomy T., \& Suryatni, M. (2015). Pengaruh Beban Kerja, Lingkungan Kerja, Dan Dukungan Sosial Terhadap Burnout Pustakawan Di Kota Mataram. Jurnal Ilmu Perpustakaan, Informasi, dan Kearsipan Khizanah Al-Hikmah, 3(2), 125-145.

Rubab, U. 2017. Impact Of Work Family Conflict On Burnout And Workplace Deviant Behavior: Mediating Role Of Stress, Jinnah Business Review.5(1).

Santoso, E.., \& Setiawan, J. L. (2018). Peran Dukungan Sosial Keluarga, Atasan, dan Rekan Kerja Terhadap Resilient Self-Efficacy Guru Sekolah Luar Biasa. Jurnal Psikologi. 45(1):27- 39.

Swasti, K. G., Ekowati, W., \& Rahmawati, E. (2016). Faktor-Faktor Yang Mempengaruhi Burnout Pada Wanita Bekerja di Kabupaten Banyumas. Jurnal Keperawatan Soedirman. 12(3): 190-198.

Szczgiel, D. D., \& Mikolajczak, M. 2018. Emotional Intelligence Buffers the Effect of Negative Emotions on Job Burnout in Nursing. Frontiers in Psychology. 2469(9).

Tawale, E. N., Budi, W., \& Nurcholis, G. (2011). Hubungan Antara Motivasi Kerja Perawat Dengan Kecenderungan Mengalami Burnout Pada Perawat di RSUD Serui-Papua. INSAN. 13(2): 74-84.

Tufail, M. S., Ismail, H., \& Zahra, S. (2016). The Impact of Work Social Support on Firm Innovation Capability: The Meditational Role of Knowledge Sharing Process and Jobc Satisfaction and Moderating Role of Organizational Trust. Pakistan Journal of Social Sciences (PJSS), 36(2).

Woodhead, E. L., Northrop, L., \& Edelstein, B. (2016). Stress, Social Support, And Burnout Among Long-Term Care Nursing Staff. Journal of Applied Gerontology, 35(1), 84-105.

Wulandari, M. T. (2018). Pengaruh Beban Kerja Terhadap Stress Kerja Melalui Dukungan Sosial Sebagai Variabel Intervening (Studi Pada Kepolisian Sektor Depok Barat). Jurnal Ekobis Dewantara. 1(7):181-194.

Yulia, A. R. (2017). Pengaruh Pekerjaan-Keluarga Dan Dukungan Sosial Serta Kecerdasan Emosional Terhadap Stres Kerja Dan Kinerja Perawat Wanita doi RSD dr. Soebandi Jember. Jurnal Bisnis dan Manajemen. 11(1):76-90. 